\title{
The economic, environmental and strategic value of biomass
}

\author{
Patrícia Carneiro, Paula Ferreira \\ Department of Production and Systems, University of Minho, Campus Azurem, 4800-058 Guimaraes, Portugal
}

\section{a $\mathrm{r}$ i c l e i n f o}

\section{Article history:}

Received 14 August 2011 Accepted 9

December 2011 Available online 30

January 2012

\section{Keywords:}

Biomass

Strategic analysis

Project evaluation

Feed-in tariff

Electricity generation a b s t r a c t

Biomass based power plants are one of the few renewable energy sources (RES) units that may be used as base load technologies, contributing also to the reduction of external energy dependency and of the greenhouse gas (GHG) emissions. The availability, heterogeneity and cost of the resource are however important barriers to the effective development and spread of these technologies. This paper aims to make a contribution to the evaluation of biomass power plants based on dedicated energy crops. The particular case of Portugal is analyzed and the strategic, environmental and economic interest of the project is evaluated under the present RES support schemes. The results suggest that the value of the assumed Feed-in Tariff (FIT) may not be enough to attract private investors' interest for these projects. The need for the creation of a specific FIT for this kind of biomass is highlighted and may be justified both by the perceived project risk and by the expected strategic and environmental value of these investments.

\section{Introduction}

One of the most relevant and worrying issues related to the energy sector concerns to the continuous increase of the external energy dependence of most countries in recent years. The growth of the pollution levels along with the shortage of the fossil fuel reserves creates additional concerns that represent strong moti-vations for the development of new power plants assumed to be environmentally friend and based on endogenous resources. The potential high efficiency of the biomass power plants along with the use of a fuel associated with renewed life cycles and their possible positive social impacts in particular at regional level, turn biomass an interesting alternative for the electricity generation [1].

Biomass is seen as an energy source that can play a key role for the fulfillment of RES goals in Europe, as it can contribute for the supply of energy in three sectors, electricity generation, heating/ cooling and transportation. The increase on the use of biomass represents also an opportunity to reach a reduction of the GHG emissions, promoting regional development, creating new job opportunities and reducing the external energy dependency of the countries.

This study addresses the issue of biomass for electricity production analyzing the strategic interest of biomass power

\footnotetext{
* Corresponding author. Tel.: p351 253511670; fax: p351 253510343.

E-mail addresses: mariapgc@hotmail.com (P. Carneiro), paulaf@dps.uminho.pt (P. Ferreira).
}

projects and the importance of incentives schemes like feed-in tariff for the economic development of the sector, in particular for the dedicated energy crops. The project evaluation is presented under the case study of the Portuguese support conditions.

Next section addresses the topic of electricity generation from biomass and the main impacts. Section 3 focuses on the economic aspects of electricity generation from biomass power plants and on RES support schemes. Section 4 presents the strategic, economic and environmental evaluation of a possible biomass power plant project based on dedicated energy crops and located in Portugal. The main conclusions are summarized at the end.

\section{Biomass for electricity generation}

Biomass is the non-fossilized and biodegradable organic mate-rial originated from plants, animals and micro-organisms [2]. Biomass is then a heterogeneous energy source and may be used to meet a variety of energy needs, including generating electricity, heating homes, fuelling vehicles and providing process heat for industrial facilities. In 2009, biomass electricity generation repre-sented $1.2 \%$ of the total electricity generated across the globe with a $6.3 \%$ share of all renewable electricity. Of those, about $71 \%$ were based on solid biomass, $16.8 \%$ were based on biogas and liquid biomass and $12.2 \%$ were based on municipal solid waste [3]. However, as the Observ'er inventory [3] underlines biomass may also be used for heating purposes, and if this is taken into account, biomass accounts for about three quarters of the world renewable energy production. On a global scale and over the longer term, large 
potential biomass production capacity can be found in developing countries and regions such as Latin America, Sub-Saharan Africa and Eastern Europe [4], creating important future opportunities for such regions with potential significant social gains. In fact, according to [5] bioenergy has the highest employment-creation potential of all RES.

\subsection{Biomass types}

The biomass that can be used for energy production may be classified as one of two types according to their origin: (i) primary biomass produced from forest or agriculture grown specifically for energy purposes (dedicated production) or (ii) secondary biomass resulting from the processing of primary biomass, including also agricultural or forestry residues, waste and subproducts. Several studies evaluating the potential supply of biomass show that the greatest opportunities for biomass production in Europe and in other places are related to the dedicated energy crops $[6,7]$.

Various cultures have been proposed or are being tested for energy production. In general, the characteristics of an ideal energy culture may be enumerated as: high output (maximum production of dry matter per hectare), low energy requirement for production, low production cost, composition with the least possible contaminants, low nutrient requirements and high dry matter yields [8,9]. Typical bioenergy crops include poplar, willow, eucalyptus and non-woody perennial grasses, such as miscanthus $[9,10]$.

Although being appointed the great opportunities for biomass production in the dedicated energy crops, currently, forest, agri-cultural and urban residues, are still the main raw materials for producing electricity and heat from biomass [11]. Nevertheless, the availability of organic waste for energy use depends heavily on variables such as economic development, consumption pattern and the fraction of biomass material in total waste production. For energy applications, which require the continued availability of biomass, it is necessary to take into account that agricultural resi-dues for example are characterized by their seasonal availability. Storage for long periods is then required, creating additional problems due to fermentation process that may lead to changes on their characteristics. As the IEA [12] recalled, those are frequently non-competitive with fossil fuels due their dispersion over large areas in small volumes.

\subsection{Biomass impacts}

There is a growing recognition of the importance of the social and environmental impacts of electricity generation activities. Although RES are generally associated to lower external impacts comparatively to fossil fuel fired plants, in particular to coal, they are not absolutely impact free.

\section{${ }_{3}$ Environmental impacts.}

As with other forms of combustion, biomass fuel combustion emits air pollutants. The amount and type of pollutants depends both on the specific combustion process involved and on the extent of controlled burning. Compared with fossil fuels, combustion plants fired with forest residues emit similar levels of nitrogen oxides, but significantly less sulphur dioxide [13].

Carbon neutrality of biomass is not accepted by all experts. ExternE results [14] indicate that biomass technologies generate very low GHG emissions in their life cycle. Many argue that carbon dioxide emissions are irrelevant because forest residue carbon is part of the natural carbon cycle, and will eventually be taken up again in new forest biomass (see for example [15] and [16]). The growing of energy crops fixes carbon from the atmosphere by photosynthetic process, this way compensating the carbon dioxide released on combustion. However, other studies indicate that carbon uptake by growing biomass occurs much more slowly than carbon release during combustion, estimating that after 80 years $13 \%$ of the carbon released from residue combustion may remain in the atmosphere [13].

Other environmental impacts of biomass include emissions from additional vehicle movements and the plant itself, environ-mental effects of herbicides, pesticides and fertilisers used during crop cultivation, any changes in soil fertility, mineral and carbon balance and ecological impacts on natural and semi-natural habi-tats and on the biodiversity supported [16]. However, according to Faaj and Domac [15] some of these adverse effects that may result from intensive cultures can be minimized and even prevented with a proper management. Also, forest management and the removal of residues can contribute to reducing fire risk, especially in forests that are currently unmanaged.

\section{${ }_{3}$ Electricity system impacts.}

Biomass is one of the few RES whose availability does not depend on weather conditions, seasonal or diurnal variations and can be stored, for use on demand [16]. This represents an important advantage, allowing electricity generation from biomass to be highly predictable and contributing to base load capacity. The possibility of combining the storage of other RES with the gener-ation of electricity from wind, hydro or solar, can be an alternative to alleviate many of the problems associated with the intermittency in the future. Additionally, it is a domestic energy source and contributes to the diversification of the fuel mix and to the security of supply.

\section{Socio-economic impacts.}

Bioenergy projects involving energy crops can make a signifi-cant contribution to rural income or employment increment. Energy crops lead to changes in agricultural labor patterns and give positive contributions to rural economic diversification [16]. Results of surveys on local public opinion of a proposed biomass gasifier in the UK indicate that potential employment impact was the most highly confirmed benefit [17]. Also, Goldemgerb [18] recognizes the generation of direct and indirect jobs as one of the main benefits of biomass. The adoption of land for the production of energy crops should be considered as a possible solution to problems such as the abandonment of land, rising unemployment and an exodus of rural areas. However, perceived negative impacts should not be forgotten. The transport and infrastructure require-ments and associated emissions of new biomass capacity may also result in an adverse reaction from sections of the local community [16]. Upreti [19] presents some examples demonstrating that a major barrier to promoting biomass energy is frequently local opposition.

\section{The economics of biomass}

An important limitation of the use of the biomass as an energy resource can be the costs. The existence of RES support schemes such as regulated feed-in tariffs or premiums, tradable green-certificates, taxes incentives or investment grants, reflect the need to ensure the interest from private investors for RES tech-nologies, representing an opportunity to reduce the risk of the project by ensuring an interesting and fixed income for a certain number of years. 


\subsection{Biomass for electricity generation costs}

Investment costs represent the total capital requirements, including the costs of power plant components, engineering, contingencies and installation [20]. This cost of capital depends largely on the technology involved, the size and energy potential of the plant. A review on recent literature [20e 25] demonstrated the difficulty to find an average value for such a diversity of technolo-gies, processes and fuels involved in biomass power projects [26]. Significant differences on the investment costs may be observed in the literature, with values varying from $1346 \mathrm{~V} / \mathrm{kW}$ to $2500 \mathrm{~V} / \mathrm{kW}$. This is also evident when analyzing the variable costs including operation and maintenance (O\&M) (see [26] for a detailed review]. The fuel cost is one of the most important parameters that influ-ence the viability of biomass plant $[22,27]$ but also a broad range of values may be found as described in Hoogwijk et al. [28]. Gan and Smith [29] for example, reported that the fuel cost accounted for approximately $50 \%$ of the total electricity cost for biomass gasifi-cation systems.

Additional aspects that strongly influence the economic viability study are: (1) the estimated installed power; (2) the estimated lifetime, frequently laying between 15 and 35 years; (3) the heat and electricity efficiency, highly depending on the type of fuel and the conversion technology used; (4) the average load factor of the power plant, as it is directly related to the electricity generated and consequently to the revenues obtained.

\subsection{Biomass support schemes: Portugal in the EU context}

There are several incentives and support schemes designed to promote the development of electricity generation from RES but FIT is by far the dominant model in EU [30]. FIT are usually established in law and ensure minimum prices established by the government and paid by utilities to generators of electricity from RES for a guaranteed minimum number of years. This way, FIT are deter-mined by politics, not necessarily by market economics [31].

As the biomass sector is extremely heterogeneous, to obtain strong conclusions from the comparison of the different countries support schemes and development of the sector is very difficult. Also, the level and importance of FIT may vary significantly among countries, depending on national characteristics such as the potential and costs of renewable resources or of the political pref-erences regarding policy instruments to promote renewable elec-tricity [32]. However, as Ragwitz et al. [33] recall due to the high share of fuel costs in total generation costs for biomass electricity technologies, the FIT systems may be less appellative for this technology than for other RES. Most of the EU countries that rely on FIT to promote biomass present differentiated values according to the technologies, type of biomass or size of the power plant.

For the particular case of Portugal for example FIT are presently regulated by DL225/2007 establishing that the FIT should be based mainly on: (1) the expected costs (fixed and variable) of new generation plants the construction of which is averted due to each RES project and (2) the expected emission costs of new generation plants the construction of which is averted due to each RES project. This last component is multiplied by a RES technology dependent factor, giving rise to the average FIT for the biomass sector in 2011 shown in Table 1.

The Portuguese Legal framework for RES to electricity genera-tion sets a temporal limitation for these remunerations for each renewable technology. For the biomass technologies this limit is set as 15 years. After these limit, the renewable power plants are ex-pected to be remunerated at market prices and by a foreseen green certificate scheme.
Table 1

Feed-in tariffs for biomass power technologies in Portugal, 2011 (source: DGGE website. Data drawn in July 2011).

\begin{tabular}{lcc}
\hline \multirow{2}{*}{ RES technology } & \multicolumn{2}{c}{ FIT (V/MWh) } \\
\cline { 2 - 3 } & 35 MW & $>5$ MW \\
\hline Forest residues & 109 & 107 \\
Municipal Solid Waste (biogas) & 117 & 115 \\
Municipal Solid Waste (direct combustion) & 54 & 53 \\
Landfill biogas & 104 & 102 \\
\hline
\end{tabular}

Regardless of the support schemes, dedicated electricity production based on biomass is still scarce and mainly based on forest residuals in Portugal. ECORYS [34] report on RES barriers in Portugal points the immaturity of the market and the availability of the resource as the main barriers for the use of biomass for elec-tricity generation. The need to develop new solutions for biomass is also underlined in this study. The Energy Plan for Portugal [35] addressed already the possibility of promoting dedicated energy crops but for the moment no special FIT is defined for this primary biomass type. On the other hand, on countries such as Italy, Spain, Sweden or Austria special incentives are given to energy crop use for electricity generation, either by subsidising the production (farmers) or by resourcing to support schemes and special regu-lated tariffs [9] although the level of support seems to vary signif-icantly between countries [36].

\section{Project evaluation}

As in many European Union countries a high incorporation of RES on the Portuguese electricity generation systems may be observed. In 2010, RES generation contributed with more than $50 \%$ for the total electricity consumed in Portugal. This high value was obtained mainly due to the strong commitment of hydro power plants, under particularly rainy conditions, combined with the increase of the wind power generation. A gradual increase in electricity generated from biomass over the years may be observed in Portugal and in 2010 electricity from biomass (dedicated and CHP solid biomass, municipal solid waste and biogas) represented $9.7 \%$ of the total electricity produced form RES and $5 \%$ of the total electricity consumption [37].

Based on the documents reviewed and on the costs assessment, this section presents the strategic, environmental and economic evaluation of a biomass electricity generation project taking into account, the estimated cost drawn from the literature and the support policies for the particular case of the Portuguese system.

\subsection{Strategic analysis}

The SWOT analysis is frequently used to describe the Strengths, Weaknesses, Opportunities and Threats for a business project or company. However, it is been also used on the analysis of energy sectors, technologies and policies [38e 40]. Fig. 1 presents a succinct SWOT analysis for the biomass power sector in Portugal, taking into account the external characteristics of the Portuguese energy system and the internal characteristics of companies presently operating in the market and of the potential projects.

In summary, biomass is one of the few RES whose availability is not dependent on weather conditions and can be stored in accor-dance with demand. Biomass electricity generation can then be highly predictable. Biomass is an endogenous energy resource and, as so, the increasing use of biomass power contributes to the security of supply, to the reduction of the external energy 


\begin{tabular}{|c|c|c|}
\hline 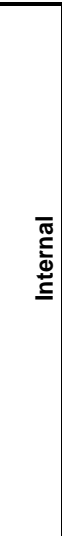 & $\begin{array}{l}\text { Strengths } \\
\text { Development of rural areas. } \\
\text { Creation of direct and indirect jobs. } \\
\text { Diversity of energy supply. } \\
\text { Reduction of soil erosion during the } \\
\text { replacement of energy fields by farmland. } \\
\text { Independence from fossil fuel markets. } \\
\text { Storage potential and possibility of generation } \\
\text { prediction. }\end{array}$ & $\begin{array}{l}\text { Weaknesses } \\
\text { Possibility of affecting the quality of soil, air, water } \\
\text { and biodiversity. } \\
\text { Possibility of using land that could be needed for } \\
\text { food production. } \\
\text { Dependence on external conditions of climate and } \\
\text { pest attacks, during the production of primary } \\
\text { source. } \\
\text { Reduced experience with dedicated energy crops. } \\
\text { Dependence of land availability } \\
\text { Economic viability dependent of regulated tariffs. } \\
\text { Cost of primary source. } \\
\text { High investment costs. }\end{array}$ \\
\hline 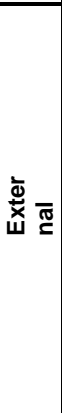 & $\begin{array}{l}\text { Opportunities } \\
\text { Biomass is a heterogeneous energy and can } \\
\text { be interesting for specific markets. } \\
\text { Market growth perspectives. } \\
\text { Energy and climate change priority on policy } \\
\text { agenda. } \\
\text { Revenues still protected by feed -in tariffs and } \\
\text { by ensured access to the grid. } \\
\text { Growth of RES plants of variable output } \\
\text { requiring backup technologies. }\end{array}$ & $\begin{array}{l}\text { Threats } \\
\text { Competition with fossil fuels and other renewable } \\
\text { sources. } \\
\text { Instability of the energy market and liberalization } \\
\text { trend of the market and of the tariffs. } \\
\text { Possibility of social opposition. }\end{array}$ \\
\hline
\end{tabular}

Fig. 1. SWOT analysis of the biomass power sector in Portugal.

dependency and protects the energy system from the fossil fuels price increase.

One of the most important strengths of biomass is the promo-tion of the development of rural areas, reducing the rural exodus and reinforcement of local industry. Another very important aspect is the possibility of creating jobs predominantly in less favored regions of the country. As potential weaknesses the possible use of land that may be needed for food production is frequently referred. There is still also a lack of knowledge about energy crops. This may delay the effective implementation of these crops as well as may put in question the farmers' decision of using the fields for the production of bioenergy. The high costs of biomass projects are also important weaknesses particularly relevant in liberalized markets or when competing with other RES such as wind and solar, for example when green-certificates schemes are considered. The high costs of investment projects of biomass and the cost of raw mate-rials are important threats to be taken in consideration.

Social opposition to these projects may be a particular relevant threat (see for example [17] and [41]). Biomass support schemes seem to remain essential to promote RES and biomass power projects in particular. It should be noted however that energy policies strongly favor these projects and this sector presents high growth perspectives for the electricity generation sector and for companies investing on it.

\subsection{Economic evaluation}

A viable substitute of fossil fuel must have not only a better environmental performance, but must also be economically competitive in order to attract investors, and at the same time must give an important contribution to change the general balance of primary energy use [42].

In this section, an economic evaluation of an electricity production project based on biomass and applied to the Portuguese system is presented. The economic evaluation was carried out by taking into account the possibility of using energy crops (mis-canthus, a promising alternative for Portugal as described in Car-neiro [26]). The fuel cost was based on Ericsson et al. [43], added of $25 \%$ for the assumed the transportation costs [10]. As no FIT are already defined for dedicated energy crops in Portugal, the value assigned to forest residuals was used and a sensitivity analysis was conducted. Three set of costs were considered and included: cost of capital, cost of maintenance and operation and fuel costs. For the determination of Net Present Value (NPV) the present value of the estimated cash-flows was computed, based on a previously defined rate of return. The Internal Rate of Return (IRR) was computed as the rate of return that equals the NPV to zero. The payback period based on discounted cashflows is also presented. The data used in economic analysis are described in Table 2.

The estimated lifetime of the plant was 20 years, but the FIT are only ensured for the first 15 years. After that, for the project eval-uation an average market electricity price of about $72 \mathrm{~V} / \mathrm{MWh}$ was assumed, enough to cover the marginal production cost of the power plant. Table 3 summarizes the obtained economic evaluation of the proposed project.

Table 2

Data used for the economic evaluation of the biomass power project.

\begin{tabular}{ll}
\hline Economic lifetime & 20 years \\
Installed power & $15 \mathrm{MW}$ \\
Heat efficiency & $56 \%$ \\
Average load factor & $44 \%$ \\
Discount rate & $10 \%$ \\
Tariff & $107 \mathrm{~V} / \mathrm{MWh}$ (first 15 years) \\
& $72 \mathrm{~V} / \mathrm{MWh}$ (last 5 years) \\
Investment cost & $1535 \mathrm{~V} / \mathrm{kW}$ \\
O\&M cost & $43.4 \mathrm{~V} /(\mathrm{kW}$ s year) $\mathrm{p} 0.004 \mathrm{~V} / \mathrm{kWh}$ \\
Fuel cost & $31.5 \mathrm{~V} / \mathrm{kWh}$ \\
\hline
\end{tabular}


The results show that the investment costs along with the fuel cost represent the highest share of the total cost for the presented case. The obtained economic indicators demonstrate that ensuring the financial viability of biomass power projects based on dedicated energy crops in Portugal may be difficult, taking into account the FIT for the sector. As Jyväskylä Innovation Oy [9] state "energy crop chains, from cultivation to power plant, are quite complex and investment costs for the plants are higher than for fossil fuel plants, it is clear that utilisation of energy crops cannot be profitable without financial support". In addition, being a new process that requires an initial research effort on the effective selection of the culture and a learning process on cultivation, harvesting and logistic handling, additional risk may be perceived and conse-quentially a higher return will be required by the investor. A recent study from Oxera [44] presented the indicative range for the discount rate attributable to biomass technologies and concluded that the risk perception is medium and the required discount rate ranged between 9 and $13 \%$ for these projects. Also Oxera [36] had already addressed this aspect and demonstrated that support schemes frequently led to IRR higher than $20 \%$ in countries such as Italy, Spain or UK. Taking this into account, a sensitivity analysis of the IRR of the project to the established FIT was conducted as shown in Fig. 2.

Assuming a regulated FIT of $150 \mathrm{~V} / \mathrm{MWh}$, a value even so lower than the one available in Spain for dedicated energy crops [9], the expected IRR of the project would be higher than $20 \%$ and the payback period would be less than 7 years. Nevertheless, even ensuring the financial viability of the project with a more inter-esting regulated FIT, the success of the project would still strongly rely on the social acceptance and commitment of farmers to this new culture. The involvement of stakeholders and local community on the project and decisions remains a fundamental aspect that should not be undervalued as demonstrated in other studies [45e 47]. In addition, the private investor and energy policy deci-sion makers must take into consideration that the promotion of energy crops for electricity generation represents an innovative project, with strategic, social and environmental gains that hardly may be addressed by a pure financial analysis. Internalising the external effects in the FIT would serve for improving the viability and implementation of electricity based on biomass, as Soliño et al. described [48].

\subsection{Environmental evaluation}

Energy production and consumption is strongly linked with the environmental pressure on the planet. For example, the emissions of $\mathrm{SO}_{2}$ (Sulphur Dioxide), $\mathrm{CO}_{2}$ and other greenhouse gases and $\mathrm{NO}_{\mathrm{x}}$ (Nitrogenous Oxides) for a certain period, depend on the amount of electricity produced and on the technological mix of the power plants operating in each electricity system during that period. The energy production and consumption represent the largest sources of greenhouse gas (GHG) emissions in the EU. The average

Table 3

Results of the economic evaluation of the biomass power project.

\begin{tabular}{ll}
\hline Cost/Income & Present value \\
\hline Investment cost & $23025 \mathrm{kV}$ \\
O\&M cost & $7511 \mathrm{kV}$ \\
Fuel cost & $27687 \mathrm{kV}$ \\
Income & $50831 \mathrm{kV}$ \\
Economic indicators & \\
NPV & $37393 \mathrm{kV}$ \\
IRR & $3.9 \%$ \\
Payback period & $>20$ years \\
\hline
\end{tabular}

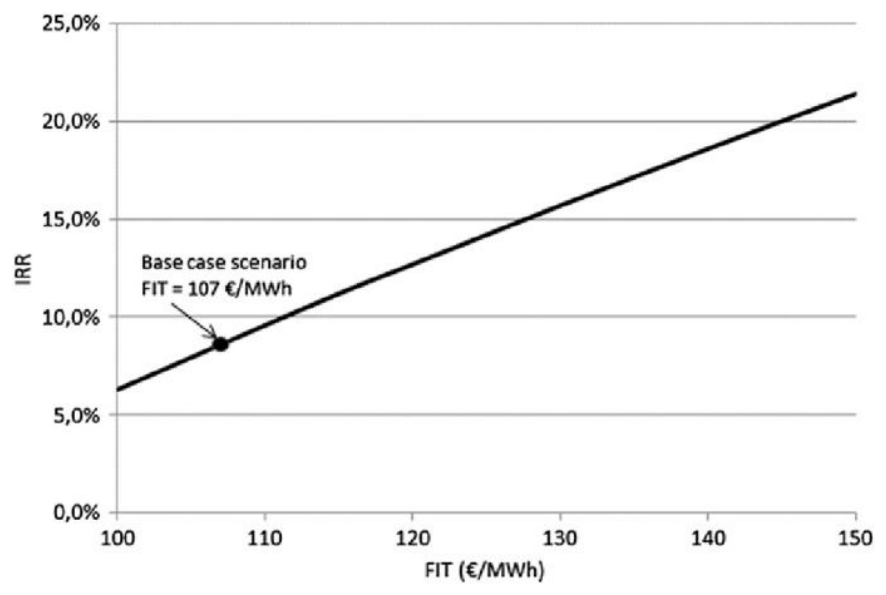

Fig. 2. Sensitivity analysis of the project results (IRR) to different FIT.

emission factor for the public electricity and heat production sector in Portugal was $311 \mathrm{~g} \mathrm{CO}_{2}$ equivalent $=\mathrm{kW}_{\mathrm{h}}$ consumed in 2008 [30]. Assuming the direct substitution and that the electricity generation from energy crops releases zero emissions; the avoided emissions from the investment under analysis may be computed as 17981 ton $\mathrm{CO}_{2}$ equivalent/year.

It should be noted that this information only allows for a rough estimation of the avoided emissions. Electricity system with high RES share will have avoided emissions much lower than the elec-tricity systems highly dependent on coal. Even so, besides the avoided emissions other external impacts associated with the biomass power projects must always be taken into consideration. These impacts, although not being easy to quantify with precision due to the heterogeneity of this type of energy, should not be ignored. The full assessment of environmental and social impacts along with the identification of the relevant stakeholders is essential for the public acceptance and effective concretization of the project [30].

\section{Conclusions}

Bioenergy is a very heterogeneous aggregation of different feeding materials, conversion technologies and end-uses. This variability in feed materials and processing technologies results in large biomass price variations. The need to develop a reliable biomass supply system makes dedicated energy crops a promising option for European Countries presenting also important social advantages. Although being the only RES that presents very significant variable costs, even surpassing the investment cost, biomass technologies can give an important contribution to the satiability of the electricity system: these power plants may operate as base load with the additional advantage of promoting both the use of endogenous resources and of releasing very low $\mathrm{CO}_{2}$ emissions.

There is a wide range of social impacts arising from the production of electricity from biomass. Food competition is ulti-mately the key social issue to be addressed. To avoid this compe-tition, energy crops need to be grown only on agricultural land not used for food crops. One of the most important social benefits of biomass production is the possibility to create direct and indirect jobs frequently in less favored regions of the counties, averting this way rural exodus and creating additional sources of income. If insensitive agriculture is replaced by less intensively managed energy crops, there are likely to be direct environmental benefits in addition to the contribution for the reduction of GHG emissions. 
This paper focused on the evaluation of the economic, strategic and environmental interest of biomass power projects based on dedicated energy crops in Portugal. The analysis demonstrated that being this sector innovative, the investment on it may bring considerable strategic advantages to investor companies leading at same time to relevant economic and social contributions. However, the inexperience about energy crops and the still required research efforts on crop selection, development and processing may delay the effective implementation of these projects putting also in question the farmers' commitment to these projects and to the use of their lands to energy crops cultivation.

The fuel cost represents an important weakness that may turn the economic return of the project difficult, under the present price conditions. The results suggest that additional support schemes are required to promote the necessary attractiveness of private inves-tors' for biomass power projects based on dedicated energy crops. In particular, and according to the present Portuguese RES policies, a more favorable and guaranteed feed-in tariff is required to tackle the still perceive risk of these projects.

Based on recent studies, the importance of the environmental impact assessment was also underlined and an estimation of the avoided $\mathrm{CO}_{2}$ equivalent emissions was attempted. A deeper analysis of the environmental impacts is however required. Future works must focus not only on emissions but also on other social relevant impacts and envisaging always the public participation on the process in order to ensure the farmers interest and commitment to the process.

\section{Acknowledgments}

This work was financed by: the QREN e Operational Programme for Competitiveness Factors, the European Union e European Regional Development Fund and National Funds- Portuguese Foundation for Science and Technology, under Project FCOMP-01-0124-FEDER-011377 and Project Pest-OE/EME/UI0252/2011.

\section{References}

[1] Carneiro P, Ferreira P. A contribution to economic evaluation of biomass energy. International Conference on Applied Business and Economics (ICABE); 2010 [La Coruna, Spain].

[2] Bhattacharva S, Salam P, Pham H, Ravindranath NH. Sustainable biomass production for energy in selected Asian countries. Biomass Bioenerg 2003;25: 471 e82.

[3] Observe'er. Worldwide electricity production from renewable energy sources. 12th Inventory - Edition, http://www.energies-renouvelables.org/observ-er/ html/inventaire/Eng/sommaire.asp\#chapitre3; 2010. Paris.

[4] Faaij A, Domac J. Emerging international bio-energy markets and opportunities for socioeconomic development. Energy for Sustainable Dev 2006;10:7e19.

[5] Hansson J, Berndes G. Perspectives on European energy pathways: description of version 1.0 of the PEEP model. Report from the European Energy Pathways project within the Alliance for global Sustainability; 2006.

[6] Ericsson K, Nilsson L. Assessment of the potential biomass supply in Europe using a resource-focused approach. Biomass Bioenerg 2006;30:1e15.

[7] Berndes G, Hoogwijk M, van den Broek R. The contribution of biomass in the future global energy supply: a review of 17 studies. Biomass Bioenerg 2003; 25:1e28.

[8] McKendry P. Energy production from biomass (part 1): overview of biomass. Bioresour Technol 2002;83:37e46.

[9] Energy from field energy crops ea handbook for energy producers. Finland: Jyväskylä Innovation Oy, http://www.encrop.net/; 2009

[10] Evans A, Strezoc V, Evans T. Sustainability considerations for electricity generation from biomass. Renew Sust Energ Rev 2010;14:1419e27.

[11] IEA Bioenergy. Annual report 2009, http://www.ieabioenergy.com/; 2010.

[12] IEA Bioenergy. Benefits of bioenergy, http://www.ieabioenergy.com/; 2005

[13] Miranda M, Hale B. Protecting the forest from the trees: the social costs of energy production in Sweden. Energy 2001;26:869e89.

[14] European Commission External. Costs research results on socio-environmental damages due to electricity and transport; 2003.

[15] Saéz R, Linares P, Leal J. Assessment of the externalities of biomass energy, and a comparison of its full costs with coal. Biomass Bioenerg 1998;14:469e78.
[16] Thornley P. Increasing biomass based power generation in the UK. Energ Policy 2006;34:2087e99.

[17] Upham P, Shackley S. Local public opinion of a proposed 21.5 MW(e) biomass gasifier in Devon: questionnaire survey results. Biomass Bioenerg 2007;31: 433e41.

[18] Goldemberg J. Brazilian energy initiative, world summit on sustainable development; Setembro, 2002. Joanesburgo, South Africa.

[19] Upreti B. Conflict over biomass energy development in the United Kingdom: some observations and lessons from England and Wales. Energ Policy 2004; 32:785e800.

[20] Carapellucci R. Power generation using dedicated woody crops: thermody-namics and economics of integrated plants. Energy 2002;27:143e59.

[21] Mirasgedis S, Diakoulaki D, Papagiannakis L, Zervos A. Impact of social costing on the competitiveness of renewable energies: the case of Crete. Energ Policy 2000;28:65e73.

[22] Gasol C, Brun F, Mosso A, Rieradevall J, Gabarrell X. Economic assessment an comparison of acacia energy crop with annual traditional crops in Southern Europe. Energ Policy 2010;38:592e7.

[23] NEEDS. Final report on technical data, costs and life cycle inventories of biomass CHP plants. Deliverable 13.2 e RS 1a. Project no: 502687. New Energy Externalitie Developments for Sustainability; 2008.

[24] IEA. Projected costs of generating electricity. Paris: OECD; 2010

[25] Roth I, Ambs L. Incorporating externalities into a full cost approach to electric power generation life-cycle costing. Energy 2004;29:2125e44.

[26] P. Carneiro. Avaliação económica da biomassa para a produção de energia. MSc thesis, University of Minho; December 2010. (in Portuguese).

[27] Boukis I, Vassilakos N, Kontopoulos G, Karellas S. Policy plan for the use of biomas and biofuels in Greece. Renew Sust Energ Rev 2008;13: 971 e85.

[28] Hoogwijk M, Faaij A, de Vries B, Turkenburg W. Exploration of regional and globa cost-supply curves of biomass energy from short-rotation crops at abandoned cropland and rest land under dour IPCC SRES land-use scenarios. Biomass Bioenergy 2009;33:26e43.

[29] Gan J, Smith C. A comparative analysis of wood biomass and coal for electricity generation under various $\mathrm{CO} 2$ emission reduction and taxes. Biomass Bio-energy 2006;30:296e303

[30] Ferreira P, Vieira F. Evaluation of an offshore wind power project: economic, strategic and environmental value. World Academy of Science, Engineering and Technology 2010;71:938e43

[31] Barclay R. Feed-in tariffs. are they right for Michigan? Michigan Electric Cooperation Association; July 2009.

[32] Sijm J. The performance of feed-in tariffs to promote renewable electricity in European countries. ECN-Ce02e083. Energieonderzoek Centrum Nederland; November 2002.

[33] Ragwitz M, Held A, Stricker E, Krechting A, Resch G, Panzer C. Recent expe-rience with feed-in tariff systems in the EU e a research paper for the International Feed-In Cooperation. A report commissioned by the Ministry for the Environment, Nature Conservation and Nuclear Safety (BMU); November 2010.

[34] ECORYS. Renewable energy non-cost barriers. AEON study Portugal, ECORYS Netherland BV, Rotterdam, http://ec.europa.eu/energy/renewables/studies/ renewables_en.htm; May 2010.

[35] MEID. Ministério da economia da inovação e do desenvolvimento. Plano Novas Energias ENE 2020; 2010 [In Portuguese].

[36] Oxera. What is the potential for commercially viable renewable generation technologies? Interim report prepared for the Department of Trade and Industry; January 2005.

[37] DGGE. Renovaveis estatisticas rápidas Maio; 2011 [in Portuguese].

[38] Markovska N, Taseska V, Pop-Jordanov J. SWOT analyses of the national energy sector for sustainable energy development. Energy 2009;34:752e6.

[39] Ozcira S, Oner Y, Bekiroglu Y. An economical aspect for energy focused SWOT analysis of Ukraine. 2009 International Conference on Clean Electrical Power, 9e11; June 2009 [Capri].

[40] European Commission. Strengths, weaknesses, opportunities and threats in energy research; 2005. Brussels.

[41] Upham P, Shackley S. The case of a proposed 21.5 MWe biomass gasifier in Winkleigh, Denvon: implications for governance of renewable energy plan-ning. Energ Policy 2006;34:2161e72.

[42] Domac J, Richard K, Risovic S. Socio-economic drivers in implementing bio-energy projects. Biomass Bioenerg 2005;28:95e266.

[43] Ericsson K, Rosenqvist H, Nilsson L. Energy crop production costs in the EU. Biomas Bioenerg 2009;33:1577e86.

[44] Oxera. Discount rates for low carbon and renewable generation technologies. Prepared for the Committee on Climate Change; April 2011.

[45] Jenssen T. The good, the bad, and the ugly: acceptance and opposition as keys to bioenergy technologies. J Urban Technol 2010;17:99e115.

[46] Stidham M, Simon-Brown V. Stakeholder perspectives on converting forest biomass to energy in Oregon, USA. Biomass Bioenerg 2011;35:203e13.

[47] Ribeiro F, Ferreira P, Araujo M. The inclusion of social aspects in power planning. Renew Sust Energ Rev. accepted for publication. in press.

[48] Soliño M, Prada A, Vázquez MX. Green electricity externalities: forest biomass in an Atlantic European region. Biomass Bioenerg 2009;33:407e14. 
